\title{
UNUSUAL WHITE-TAILED DEER BEHAVIOR
}

JAMES A. CARSON, 565 Linden Avenue, Winnipeg, Manitoba, R2K 0N9.

While bowhunting for deer in the Winnipeg vicinity on the evening of 10 November 1979, at approximately 1630 , I made an unusual observation which I should like to record. What I saw was unusual in the sense that l've never seen it before during eight years hunting white-tailed deer in similar circumstances, nor have I ever read anything approaching it.

I had my tree stand set some 40 paces from two buck scrapes on the edge of a bluff or grove of trees. The habitat consisted of a mixture of oak, ash, elm and maple. Secondary growth was hazel and chokecherry. The area was fairly open. From 12 feet up in my stand I could see a fair distance in all directions. The ground had a light cover of snow which increased the capability of observing all nearby animal movements (Diagram no. 1).

Two white-tailed deer appeared. One was a doe, quite large, the other, which was smaller, appeared to be a yearling doe (spring 1979). When the two animals got within 50 yards or so, the smaller doe trotted over to one of the scrapes, meanwhile shaking its head from side to side. Upon reaching the scrape, she proceeded to jump up and down on it with all four feet lifting off the ground at the same time. Ears bent forward, legs very stiff, and tail straight in the air, she made a peculiar sight (Diagram no. 2).

She repeated this four times, then started biting at the branches above the scrape, virtually trying to break them off higher up, above what had been broken previously. Seconds later she kicked leaves and grass in a frenzy of activity. Scampering and playing like a dog, retreating from the scrape for several yards, then within the same moment running back to the scrape, neck stretched, nose down and smelling the bare ground. As she approached, she extended her front legs forward, hunching her back like a dog stretching, and shuffled backwards at a rapid pace. Doing this

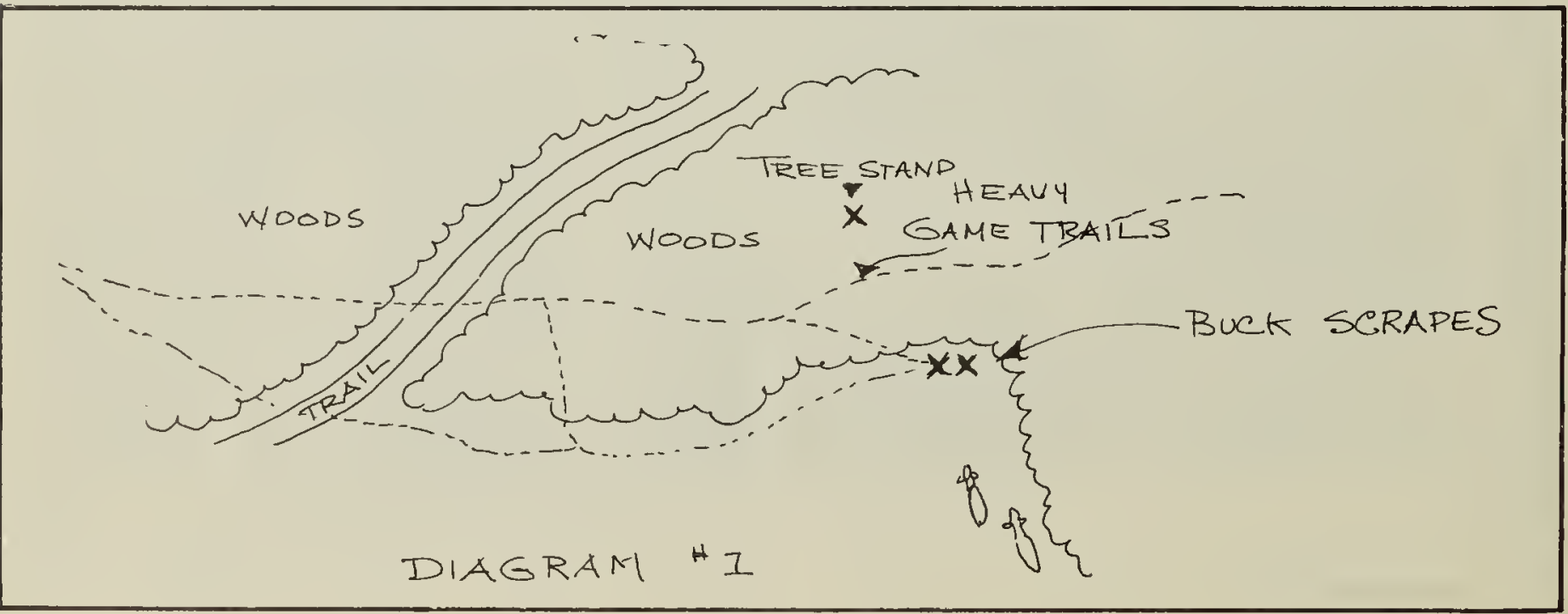




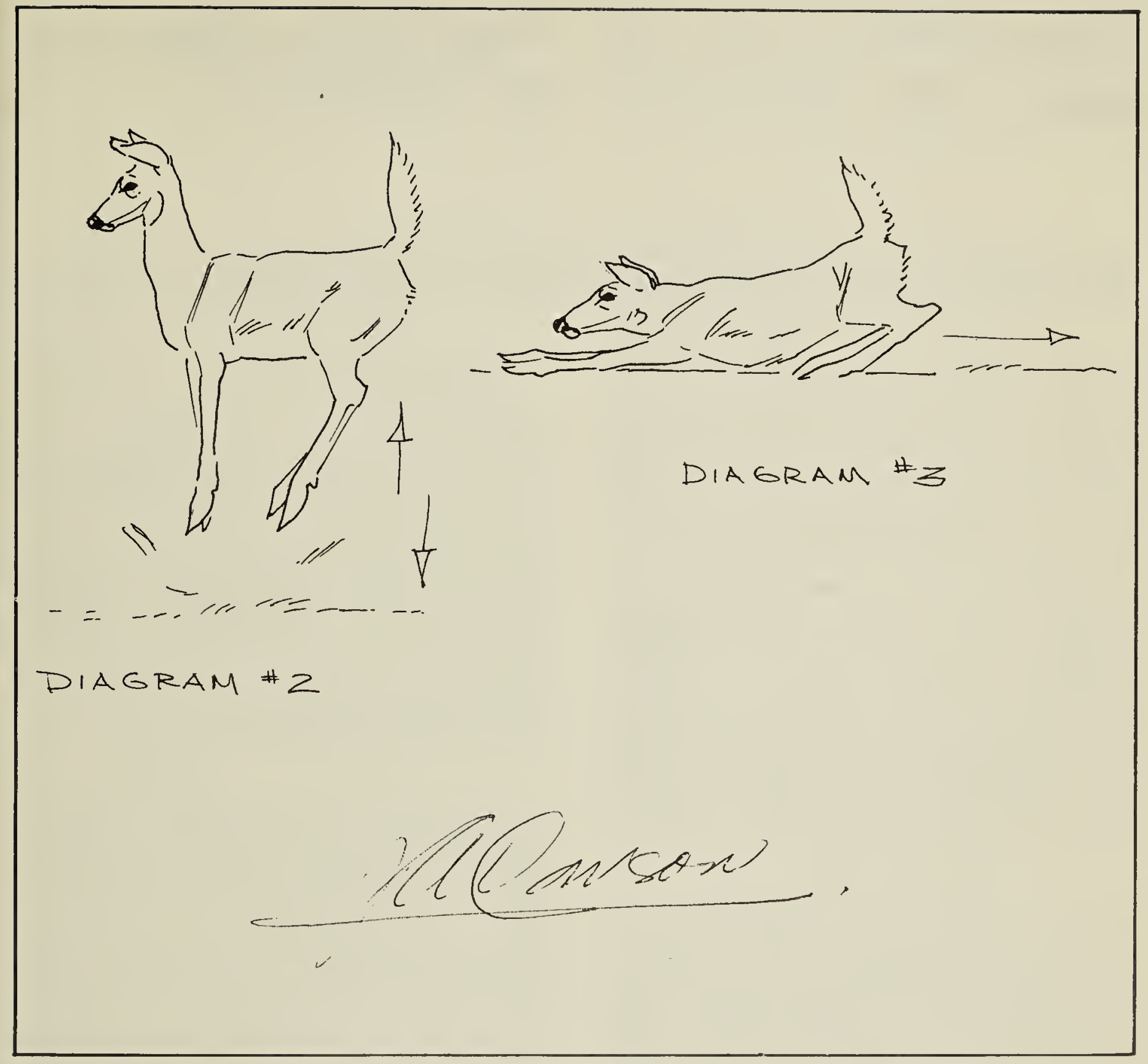

twice, she returned to the scrape to jump on it three more times with the stiff-legged posture. Then she walked away for several feet, urinating on the trail. She then ran down the trail in a terrific burst of speed, disappearing from sight (Diagram no. 3).

The larger doe approached the scrape at a walk and proceeded to bite the branches and paw the ground. She performed basically the same actions of those of the younger animal, but with more premeditated movements. At the end of the sequence she urinated in the middle of the scrape, turned, smelled the urine, and again with a sudden burst of energy followed the younger doe and disappeared.

\section{SASKATCHEWAN CHRISTMAS MAMMAL COUNT}

Reports of mammals seen during the Christmas Bird Counts will be compiled again this year. When making your Christmas Bird Count, please note the number of each species of mammal seen, and the species of tracks that you can positively identify.

Send the list with your Bird Count by January 15,1981 , at the latest, to Mrs. Mary I. Houston, 863 University Drive, Saskatoon, Sask. S7N 0J8. 